
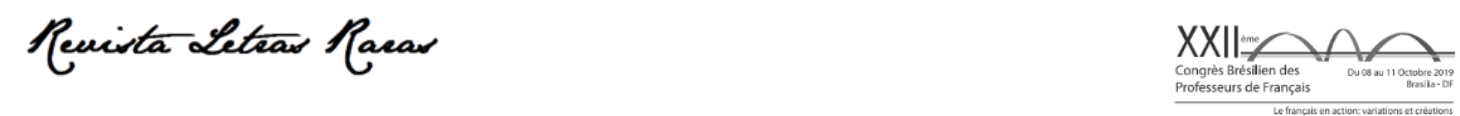

Actes du XXIlème Congrès brésilien des professeurs de français (dans Édition spéciale de la Revue Letras Raras 2020)

ISSN : 2317-2347 - v. 9, Dossier Spécial (2020)

Todo o conteúdo da RLR está licenciado sob Creative Commons Atribuição 4.0 Internacional

\title{
Diri ak pwa, I'histoire haïtienne et la transition migrante dans Adeus Haiti, d’Edwidge Danticat
}

\section{Maria Helena Valetim Duca Oyama*}

Professeur au Cours de Lettres, Portugais et Français à l'Université Fédérale de Roraima

iD https://orcid.org/0000-0003-2297-882X

Reçu le 21 oct. 2020. Approuvé le 09 nov. 2020.

Comment citer cet article:

OYAMA, MARIA HELENA VALENTIM DUCA. Diri ak pwa, I'histoire haïtienne et la transition migrante dans Adeus Haiti, d'Edwidge Danticat. In: CONGRES BRESILIEN DES PROFESSEURS DE FRANÇAIS, 22., 2019, Brasília. Actes du XXIIème Congrès Brésilien des Professeurs de Français. Édition spéciale de la Revue Letras Raras: Campina Grande. EDUFCG. nov. 2020, p. 429-439.

\section{RÉSUMÉ}

Après les réflexions d'Aimé Césaire (1983) dans son poème Cahier d'un retour au pays natal, celles d'Édouard Glissant $(1990$; 1997) à propos de la Poétique de la Relation, de la Créolisation et du Tout Monde et celles de Bernabé, Chamoiseau et Confiant (1989) sur la Créolité, la littérature caraïbéenne se présente comme une littérature tout à fait post-coloniale, une littérature qui présente un mode différent de réfléchir sur les questions identitaires. Cet article a l'objectif de discuter la relation entre mémoire, histoire et littérature à partir du récit Adeus Haiti, d'Edwidge Danticat (2010), écrivaine d'origine haïtienne qui vit aux États-Unis. L'étude de l'oeuvre tient en compte l'idée de "traces» (GLISSANT, 2005), comme le pouvoir de (re)construire la mémoire, le passé à partir des moments du présent d'une communauté, d'une famille dont l'adaptation dans un autre territoire, dans un autre contexte culturel passe par une «transition» formelle, par le diri ak pwa.

MOTS-CLÉS : Haiti; Littérature; Histoire; Edwidge Danticat; Diri ak pwa.

\section{Introduction}

L'objectif de cet article est de discuter le thème de la migration et sa relation avec mémoire et histoire, à partir du récit Adeus Haiti, traduction publiée em 2010 en langue portugaise de l'anglais Brother, I'm Dying, d'Edwidge Danticat (2007), écrivaine d'origine haïtienne vivant aux États-Unis. Le récit est écrit en deux parties; la première a le titre "C'est mon frère» et la deuxième, «Pour l'adversité»; cette partie est annoncée à sa première page suivie d'un proverbe «Un ami aime toujours, et un frère naît pour l'adversité. PROVERBES 

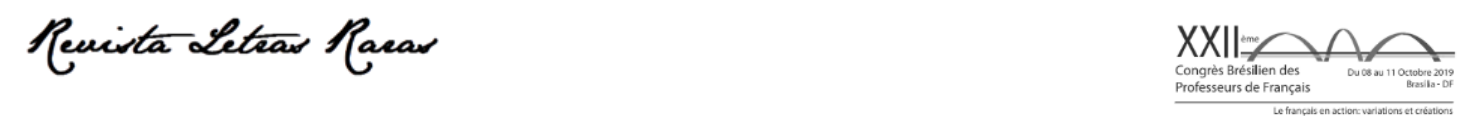

Actes du XXIlème Congrès brésilien des professeurs de français (dans Édition spéciale de la Revue Letras Raras 2020) ISSN : 2317-2347 - v. 9, Dossier Spécial (2020)

Todo o conteúdo da RLR está licenciado sob Creative Commons Atribuição 4.0 Internacional

17,17» (DANTICAT, 2010, p. 109). Cela montre déjà les liens entre frères, mais surtout la loyauté de Tio Joseph et du Père de Danticat, fils conducteurs qui guident le récit. Les deux parties du récit, présentent des événements liés aux déplacements des membres de la famille Cat entre Haïti et les États-Unis, leur adaptation dans ce pays-ci et aux jours difficiles du gouvernement duvalieriste.

Le récit est écrit dans l'espace de l'Autre, des nord-américains et suit un parcours de retour à l'enfance, plein d'histoires haïtiennes liées aux douleurs et aux sursauts de la violence dans toutes ses formes. Ces douleurs du passé s'entrecroisent aux douleurs mais aussi au bonheur de la transition migrante dans cet espace où tout est à découvrir, à comprendre et à apprendre en dépit du passé haïtien; c'est ce que l'on peut observer dans le rituel du diri ak pwa, les ingrédients du plat typique de Haïti qui permettra à I'haïtien de comprendre sa condition migrante dans le monde nord-américain. Le diri ak pwa se présente aussi comme un aliment du courage pour supporter un passé inoubliable et qui dénonce la violence d'avant mais qui aide à comprendre la violence d'aujourd'hui et qui (ré)invente des formes de résistance contre toute forme d'oppression aux citoyens haïtiens, aux citoyens caraïbéens.

\section{L'idée de « trace », Histoire et histoires}

L'étude de ce récit tient en compte l'idée de «trace», du poète, essayiste et romancier Edouard Glissant, de la Martinique. Les traces, selon Glissant (2005), sont liées au pouvoir de (re)construire la mémoire, le passé d'une communauté, et on pourrait ajouter, la (re)construction d'une famille dont l'adaptation dans un autre territoire, un autre contexte historique et culturel, passe par une « transition » formelle, par la dégustation du diri ak pwa, le plat typique de la cuisine haïtienne, qui représenterait l'émotion du retour au pays natal et aussi une prise de conscience de la condition migrante, c'est-à-dire un chemin ouvert à l'avenir, sans peur de ce que l'on trouvera, car l'avenir est imprévisible soit au niveau de la langue parlée, soit au niveau de la reconstruction de chaque fait du passé douloureux ou des manifestations culturelles. Pour Glissant (2005), le migrant :

recompose, à travers des traces / résidus, un langage et des manifestations artistiques, que l'on pourrait dire valables pour tous. Par exemple, une communauté ethnique sur le continent américain a conservé le souvenir des chants chantés lors des funérailles, mariages, baptêmes, qui expriment la 

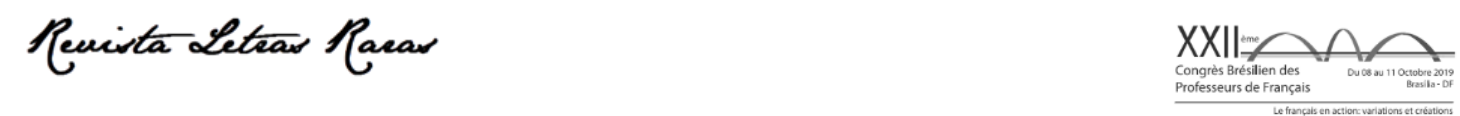

Actes du XXIlème Congrès brésilien des professeurs de français (dans Édition spéciale de la Revue Letras Raras 2020)

ISSN : 2317-2347 - v. 9, Dossier Spécial (2020)

Todo o conteúdo da RLR está licenciado sob Creative Commons Atribuição 4.0 Internacional

douleur, la joie, venant de l'ancien pays d'origine, et qui ont été chantés depuis cent ans ou plus et à plusieurs reprises. la vie de famille. Désormais, l'Africain déporté n'avait pas la possibilité de conserver ce type d'héritage spécifique. Mais il a créé quelque chose d'imprévisible basé uniquement sur les pouvoirs de la mémoire, c'est-à-dire uniquement à partir des pensées de la trace / résidu, qu'il avait laissé : il a composé des langues créoles et des formes d'art valables pour tous, comme la musique jazz, qui est reconstruit à l'aide d'instruments adoptés par eux, mais à partir de traces / résidus de rythmes africains fondamentaux (GLISSANT, 2005 p. 19). ${ }^{1}$

La relation entre Histoire/histoires et littérature dans le récit de Danticat est claire, celle-ci tisse les fils conducteurs des fragments de I'Histoire officielle avec ceux des histoires racontées en famille, par des cousins, oncle, mère et père; elle suit les traces, les vestiges de ce qui reste, ce qu'elle même témoigne, comme Edwidge (2007) :

Escrevo estas coisas agora, algumas como as testemunhei e recordo hoje, outras, a partir de documentos oficiais, bem como a baseada em lembranças compartilhadas de membros da família. Mas a essência delas foi contada a mim ao longo dos anos, em parte por meu tio Joseph, em parte por meu pai. Algumas contadas de qualquer jeito, apressadamente. Outras, com mais detalhes. Ouvi-as fora de sequência e fragmentadas. Esta é uma tentativa de coesão e de recriar alguns poucos meses maravilhosos e terríveis, quando suas vidas e a minha se cruzaram de maneira espantosa, forçandome a olhar para a frente e para trás ao mesmo tempo. Só estou escrevendo isto porque eles não puderam (DANTICAT, 2010, p. 31).

Ce sont des histoires vécues pendant son enfance et son adolescence auprès de Tio Joseph, à la capitale haïtienne et après, chez ses parents, aux États-Unis. La reconstruction d'une nouvelle vie, la famille se réinvente comme un fruit du cyclone, comme préfigure

\footnotetext{
1 Notre traduction de : recompõe, através de rastros/resíduos, uma linguagem e manifestações artísticas, que poderíamos dizer válidas para todos. Por exemplo, uma comunidade étnica do continente americano preservou a memória dos cantos entoados nos funerais, casamentos, batismos, que expressam a dor, a alegria, vindos do antigo país de origem, e que são cantadas há cem anos ou mais e em diversas ocasiões da vida familiar. Ora, o africano deportado não teve a possibilidade de manter essa espécie de heranças pontuais. Mas criou algo imprevisivel a partir unicamente dos poderes da memória, isto é, somente a partir dos pensamentos do rastro/resíduo, que the restavam: compôs linguagens crioulas e formas de arte válidas para todos, como, por exemplo a música de jazz, que é re-construída [sic] com a ajuda de instrumentos por eles adotados, mas a partir rastros/resíduos de ritmos africanos fundamentais.
} 

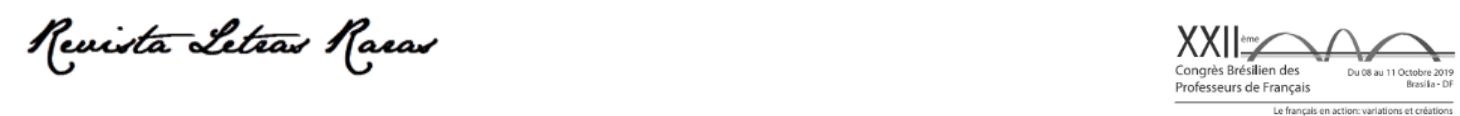

Actes du XXIlème Congrès brésilien des professeurs de français (dans Édition spéciale de la Revue Letras Raras 2020) ISSN : 2317-2347 - v. 9, Dossier Spécial (2020)

Todo o conteúdo da RLR está licenciado sob Creative Commons Atribuição 4.0 Internacional

l'essayiste de la Guadalupe Daniel Maximin (2006), qui relie la géographie de la région caraïbéenne à la matrice d'une géopoétique de cette région. Pour Maximin, la manière de vivre et la manière de faire, et j'ajouterais les manières de lutter, seraient les caractéristiques des fruits $d u$ cyclone, fruits des intempéries, puisque les caraïbéens traversent une sorte de voyage initiatique quand ils voient et vivent, dès très tôt, les effets des orages, d'un volcan en éruption, des tremblements et des inondations (MAXIMIN, 2006).

On observe que le traducteur de Brother, I'm Dying, Geraldo Galvão Ferraz, a choisi le titre Adeus Haiti parfaitement, même si le terme, frère, brother, en anglais, n'apparaît pas dans le titre de la traduction. On peut croire que dans le titre original le terme brother représente tout le pays/Haïti dans plusieurs sens, soit par la condition de Tio Joseph, qui annonce sa grave maladie à la gorge à son frère, père d'Edwidge et fait ses adieux, soit par le fait que Tio Joseph représente un livre d'histoire, de l'histoire haïtienne, voire une bibliothèque complète, en allusion à la mort d'un griot africain ou d'un chef indigène des Amériques, porteur du savoir, des connaissances transmises dans les communautés, par l'oralité. Donc, le choix du titre Adeus Haïti! est bien choisi, mieux que Adeus, irmão! ou tout simplement Irmão, estou morrendo! Mon intention dans cette étude est de chercher les traces de l'Histoire et des histoires, ainsi que le rituel de la transition migrante dans le récit.

Dans Adeus Haiti Danticat reprend la saga de la famille Cat en territoire nord-américain à la recherche des meilleures conditions de vie, dans une ambiance où I'histoire de douleur ne pourra peut-être pas se répéter. Mais c'est la douleur de ce passé, qui va assurer un meilleur avenir aux Cat, aux haïtiens et aux caraïbéens en général.

Pour rejoindre, recomposer ces histoires, elle présente les membres de la famille comme des héros, colibris de la résistance dans des territoires éloignés, comme des colibris qui reconstruisent bravement ce qui a été ravagé, sa lutte journalière. Ses souvenirs servent à reconstruire I'histoire de manière prophétique, comme a défendu Glissant (2005), le passé doit être rêvé et il suggère à I'historien et aux romanciers, la tâche de (re) écrire les conditions initiales qui (dé)figurent le présent d'une communauté, d'un pays.

I| faudrait considérer dans la proposition glissantienne que, quand on revient à ces «conditions initiales» on revoit obligatoirement l'Histoire officielle, et par conséquent, on récupère ce qui est caché dans l'inconscient de ceux qui ont été marginalisés, c'est-à-dire, les colonisés, les opprimés. Cette vision, qui a déjà été évaluée plusieurs fois comme un processus douloureux, 

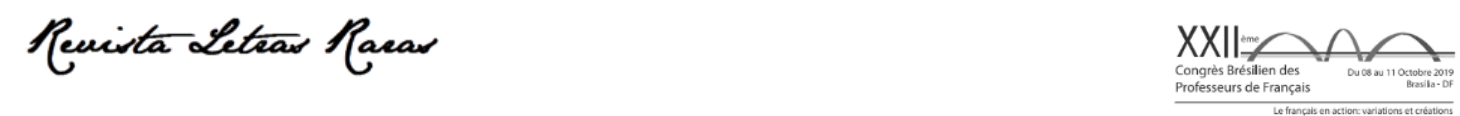

Actes du XXIlème Congrès brésilien des professeurs de français (dans Édition spéciale de la Revue Letras Raras 2020) ISSN : 2317-2347 - v. 9, Dossier Spécial (2020)

Todo o conteúdo da RLR está licenciado sob Creative Commons Atribuição 4.0 Internacional

a été considérée aussi nécessaire pour surmonter des obstacles, pour découvrir de nouvelles formes, de nouveaux gains et des solutions à des problèmes futurs.

\section{Les histoires de violence et de résistances}

Les traces, les vestiges de l'histoire de Haïti remonte à plusieurs moments de la résistance de ses citoyens: d'abord, à celui de la préparation de la Révolution de SaintDomingue qui a eu comme résultat l'indépendance politique de l'île, en 1804; puis, à la célèbre révolte des Cacos, où la population paysanne, sévèrement réprimée (de 1915 à 1934), a expulsé les soldats nord-américains en 1934 ; puis encore à la Traite verte, comme l'affirme René Depestre :

II s'agissait de l'émigration massive de milliers de paysans haïtiens pauvres et sans terre, pour travailler dans les champs de canne à sucre de Cuba et de la République dominicaine, dans des conditions de travail inhumaines (DEPESTRE, 1980, p. 188-9).

L'histoire de résistance haïtienne a vécu la dictature de Duvalier; en 1957, quand le médecin François Duvalier (Papa Doc), nègre, apparaît comme représentant du vodou, religion du peuple haïtien, mais s'est transformé en un dictateur au pouvoir et y est resté de 1957 a 1971. Pour la population pauvre, il se proposait à lutter contre l'oppression des politiciens, des militaires, des propriétaires de terre et de commerçant mulâtres, ce qui a malheureusement stimulé la discrimination raciale. II a également établi la présidence à vie et héréditaire dans les années 1960, ce qui a permis à son fils Jean-Claude Duvalier de rester au pouvoir jusqu'en 1986: «Dictateur anti-mulâtre et anti-communiste, soumis au département d'Etat américain (...) il était favorable à l'ouverture de l'île aux dollars des touristes américains (ANTOINE, 1992).

Selon Hurbon (1988), Jean-Claude Duvalier, le Baby Doc a perpétué la terreur, il «a appliqué les thèses de l'idéologie raciale et nazie à la société haïtienne» (HURBON, 1988, p. 70), au point de créer la police secrète, en 1960, les «célèbres» Tontons Macoutes. C'étaient des policiers spéciaux qui ont agi brutalement et qui étaient maintenus par le gouvernement pour poursuivre, torturer et assassiner des prisonniers politiques. Pendant longtemps, selon Hurbon (1988), ils ont initié «un génocide haïtien», un régime de terreur qui a entraîné la mort de plus de 

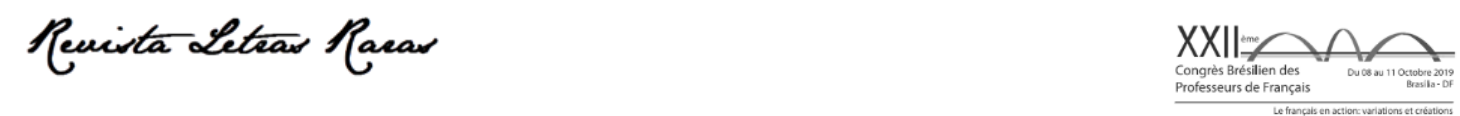

Actes du XXIlème Congrès brésilien des professeurs de français (dans Édition spéciale de la Revue Letras Raras 2020) ISSN : 2317-2347 - v. 9, Dossier Spécial (2020)

Todo o conteúdo da RLR está licenciado sob Creative Commons Atribuição 4.0 Internacional

30000 Haïtiens. Personne ne pouvait s'exprimer, donner des opinions, puisque le gouvernement a créé la censure de la presse. Comme le souligne Antoine (1992), en plus des morts, un million d'Haïtiens sont partis en exil.

Mais les défis se sont poursuivis après la chute de la dictature Duvalier en 1986. Plusieurs gouvernements intermédiaires ont été imposés, comme Leslie Manigat (1988-1989), renversé par un coup d'État militaire par le général Henri Namphy (1989) jusqu'à Jean Bertrand Aristide, ancien prêtre catholique représentant la théologie de la libération, élu par la grande majorité de la population en 1991 avec la promesse de veiller sur les pauvres et de réactiver les droits constitutionnels, s'est avéré être un leader noir charismatique et démocratique, le premier après 1804 , ayant été le président qui avait le plus grand soutien populaire. II a également subi un coup d'État militaire et a quitté le pays la même année. Après plusieurs présidents déposés, comme Raoul Cedras, chef du coup d'État, qui a subi des sanctions économiques dictées par les Nations Unies en 1993, les forces armées américaines ont envahi l'île en 1994, avec la justification de la restauration du système électoral démocratique. Jean-Bertrand Aristide est revenu au pouvoir mais, paradoxalement, il a repris des pratiques politiques dictatoriales, provoquant des actions de milices dans les quartiers de Port-au-Prince en 1995, où des meurtres constants ont été enregistrés.

Aussi déposé, Jean-Bertrand Aristide s'est enfui en Afrique et le pays a été occupé par des «soldats de la paix» de l'ONU formés par des armées de plusieurs pays, dont le Brésil, une action dénoncée aussi par Danticat.

Danticat suit ces traces historiques dans son récit par les témoignages de Tio Joseph; les histoires des élections, dépositions et reconductions des présidents au pouvoir mais surtout les traces des répressions du peuple haïtien :

15 de julho de 2004, o quinquagésimo aniversário de Jean-Baptiste Aristide, o presidente duas vezes eleito e duas vezes deposto do Haiti. Afastado do poder em fevereiro de 2004, por uma ação conjunta da França, do Canadá e dos Estados Unidos, Aristide agora estava passando seu aniversário no exílio, na África do Sul (DANTICAT, 2010, p. 30).

Em 7 de fevereiro de 1986, no aniversário de 63 anos do meu tio, JeanClaude 'Baby Doc' Duvalier fugiu do Haiti para a França, deixando uma junta 

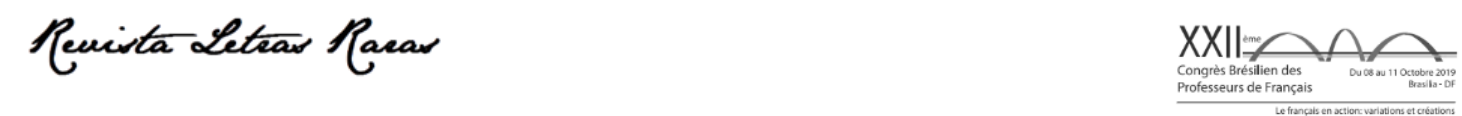

Actes du XXIlème Congrès brésilien des professeurs de français (dans Édition spéciale de la Revue Letras Raras 2020)

ISSN : 2317-2347 - v. 9, Dossier Spécial (2020)

Todo o conteúdo da RLR está licenciado sob Creative Commons Atribuição 4.0 Internacional

militar governando o país. A junta, que esteve no poder por dois anos, era liderada por um ambicioso oficial do Exército, o tenente-general HenriNanphy. Um novo presidente, Leslie Manigat foi derrubado pelo tenente Prosper Avril. Em abril de 1989, um grupo de ex-Tontons-Macoutes e legalistas da linha dura de Duvalier tentou derrubar Avril num golpe fracassado, criando hostilidades dentro do Exército (DANTICAT, 2010, p. 116).

On peut observer que l'anniversaire du président déposé est enregistré dans ses mémoires, comme l'est aussi celui de Tio Joseph; l'anniversaire, la fête chez l'enfant Edwidge qui a trop entendu, trop vu.

Ces traces de la dispute politique entre gouverneurs haïtiens ont aussi un double sens; un anniversaire est, dans ce cas, plus qu'un anniversaire, sans fête, plus qu'un an de vie, c'est la possibilité d'avoir échappé à la violence :

Em 1990, o general Prosper Avril renunciou, dando lugar às eleições de dezembro de 1990, nas quais um jovem padre chamado Jean-Baptiste Aristide, que reunira uma quantidade maciça de seguidores graças aos seus ousados sermões contra os Duvalier, conseguiu 67 por cento dos votos. Aristide foi empossado em 7 de fevereiro de 1991, no aniversário de 68 anos do meu tio. (DANTICAT, 2010, p. 120)

Mas apenas sete meses depois, em 30 de setembro de 1991, Aristide foi deposto por um golpe militar. Fugiu para a Venezuela, depois para Whashington, onde ficou por três anos. Porém, como a maioria da população que o elegera ansiosamente, os moradores de Bel Air foram inflexíveis ao pedir a sua volta por meio de protestos e manifestações. 0 Exército retaliou invadindo e incendiando casas, matando centenas dos vizinhos de meu tio. (DANTICAT, 2010, p. 120)

Ainsi, on peut voir la critique à la création de la police parallèle, les Macoutes, surtout son aspect le plus violent, qui est la destruction de l'avenir des jeunes, forcés à suivre les groupes 

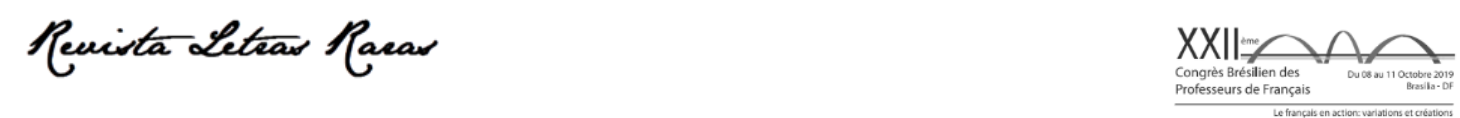

Actes du XXIlème Congrès brésilien des professeurs de français (dans Édition spéciale de la Revue Letras Raras 2020)

ISSN : 2317-2347 - v. 9, Dossier Spécial (2020)

Todo o conteúdo da RLR está licenciado sob Creative Commons Atribuição 4.0 Internacional

radicaux du duvalierisme. Pressoir, un ami d'enfance de la famille Cat, est au centre de cet épisode de l'histoire récupérée dans la narrative, avec la violence imposée à tous les haïtiens :

Vestido com uniforme jeans dos Tonton Macoutes, Pressoir esperava na nossa varanda, onde Nick, Bob e eu estávamos brincando...

Ele usava os óculos escuros espelhados que eram a marca registrada dos macoutes e escondiam completamente seus olhos. Também usavam arma a partir de algum momento como macoute, mas ainda não era a o caso de Pressoir. (DANTICAT, 2010, p. 74)

Um homem cujos olhos não se podem mirar não é um homem em que se possa jamais confiar. (DANTICAT, 2010, p. 76)

- Pressoir agora é um grande chefe de verdade, um macoute da cidade. Nenhum de nós pode traí-lo. (DANTICAT, 2010, p. 76)

Danticat montre la progression de la violence contre les jeunes car la carrière dans le monde des disputes des Macoutes dans la région de Bel Air, où Tio Joseph habitait; Edwidge, petite fille, voit Pressoir au début de cette carrière vers la mort.

Les traces de la violence mettent en relief aussi la perte des innocents, des citoyens. Les balles perdues cherchent et ciblent des gens comme Marie-Micheline, une voisine à Bel Air:

A luta entre as facções militares contrárias chegou a Bel Air certa tarde de abril, quando um grupo expulsou o outro para a rue Tirremasse e para 0 portão de ferro batido da clínica da igreja. Marie Micheline estava sentada sozinha, atrás de uma mesa, olhando para algumas anotações suas sobre os cerca de vinte pacientes que veria naquele dia. (DANTICAT, 2010, p. 116117)

- Vizinhos viram-na de pé na porta com gotas de suor surgindo na testa. Então, uma bala silvou, balançando o portão com uma faísca. (DANTICAT, 2010, p. 117) 

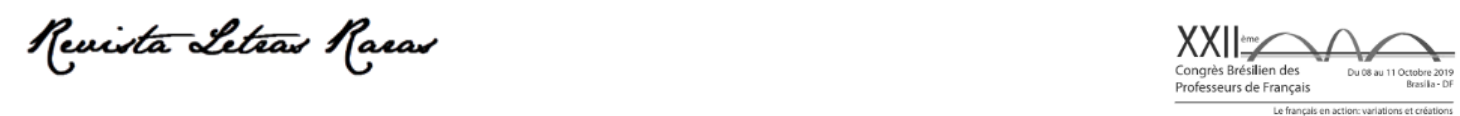

Actes du XXIlème Congrès brésilien des professeurs de français (dans Édition spéciale de la Revue Letras Raras 2020) ISSN : 2317-2347 - v. 9, Dossier Spécial (2020)

Todo o conteúdo da RLR está licenciado sob Creative Commons Atribuição 4.0 Internacional

La mort de Marie Micheline représente le sommet de la violence, c'est l'invasion de l'intimité de tous ceux qui attendent la paix chez soi. Mais la résistance de la population effrayée, est mise en relation avec le courage de Tio Joseph de réunir les fragments des corps humains victimes de la violence; son attitude représente l'humanité encore présente dans le monde; les habitudes de Tio Joseph, pareilles à celles de l'esprit colibri (cet oiseau qui se bât les ailes à (re)construire) même s'il ne pouvait que:

registrar o saldo dos mortos que conseguia ver: Durante os anos em que podia falar, desenvolvera um hábito de registrar coisas, então listou os cadáveres nos bloquinhos que sempre levava no bolso do paletó. Escrevia os nomes das vítimas, quando as conhecia, as condições de seus corpos e a hora em que eram recolhidas, por membros das famílias ou serviços de limpeza, para serem transportadas para o necrotério ou jogadas em valas comuns.

Jonas, talvez 20 anos, sem a mão direita, $11 \mathrm{~h} 35$

Gladys, talvez 35 anos, nu, $15 \mathrm{~h} 09$

Samuel, 75 anos, engraxate, $17 \mathrm{~h} 42$

Homem desconhecido, talvez 25 anos, rosto mutilado, $21 \mathrm{~h} 17$ (DANTICAT, 2010, p. 121)

Elle montre la révolte cotre la condition sociale de misère vécue par les habitants de Bel Air; on y voit, en tant que lecteur, l'ironie par rapport aux actions des Macoutes qui ne cessent d'agir, même aux moments de deuil familier pendant l'enterrement de Tante Denise, épouse de Tio Joseph: 'Denise, sè mwen, irmã, o que é isso, uma salva de 21 tiros? Você não é militar, Denise. Você não é policial. Por que estão atirando no seu enterro?' (DANTICAT, 2010, p. 134).

Danticat critique aussi l'excès de violence par la création par I'ONU de la MINUSTAH Mission des Nações Unidas pour la Sensibilisation a Haïti, mission de stabilisation lidérée par le Brésil. (DANTICAT, 2010, p. 114); elle montre que cette action ne résout pas les problèmes de la population car son pouvoir armé efface l'identité des communautés, ses traditions, les histoires des haïtiens de la région de Bel Air et Cité Soleil, deux quartiers très peuplés de la capitale haïtienne. 

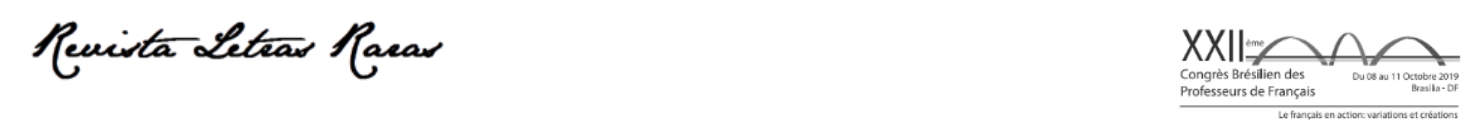

Actes du XXIlème Congrès brésilien des professeurs de français (dans Édition spéciale de la Revue Letras Raras 2020) ISSN : 2317-2347 - v. 9, Dossier Spécial (2020)

Todo o conteúdo da RLR está licenciado sob Creative Commons Atribuição 4.0 Internacional

Adeus, Haiti (2010) peut être analysé par l'affectivité, puisque le fil conducteur du récit mène le lecteur à sentir, la façon dont toute la famille Cat a résisté et surmonté leurs problèmes sur le territoire nord-américain. Dans cette courte analyse présentée ici, on voit que l'aspect historique s'entrecroise avec le politique. Danticat critique la violence à laquelle les migrants sont exposés même dans nos jours, où le capitalisme détruit les histoires. Mais il y a l'esprit résistant dans la littérature, le fait de ré(élaborer) les histoires pour qu'elles ne soient pas oubliées.

Dans le récit de Danticat (2010), il y a l'idée de recherche, de quête, un parcours familier, une traversée sans limites observée de plusieurs manières, soit par l'espace de Bel Air où elle est née, en Haïti, soit par l'espace nord -américain où elle rencontre sa stabilité, son travail, sa nouvelle vie, son mariage, sa fille dans son ventre. Cependant, elle vit aussi la logique de l'Autre, la logique du passeport, du visa, de la contre-affirmation identitaire, une géopoétique du postmoderne, où tout est liquide, mais elle vit aussi la quête de l' espace, la conscience des liens qui unissent les membres de sa famille.

C'est une géopoétique qui valorise l'image de la famille protectrice où elle pourra s'attacher et où elle pourra revenir pour revoir ses origines dans le territoire nord-américain.

Le diri ak pwa est le lien avec Haïti dans le récit; dans la cuisine, le riz et les haricot secs sentent la mémoire:

A primeira refeição de minha mãe no Brooklyn foi quase igual à de Bob e a minha. Consistia de frango assado, tranchagens doces fritas, que minha mãe adora, e diri ak pwa, arroz com feijão.

Por algum tempo, cada vez que alguém do Haiti ia nos visitar, meu pai ajudava a fazer esta mesma refeição, exatamente como fez para nós, um banquete de boas-vindas, como a chamava, porque queria que suas visitas comessem algo que havia nutrido sua transição para a vida de imigrante. $\mathrm{E}$, mesmo que a estadia dessas pessoas não fosse ser tão longa quanto a sua, ele esperava que elas sentissem, como ele, que alguém poderia facilmente voltar para casa simplesmente levando um garfo até a boca. (DANTICAT, 2010, p. 220)

Manger le diri ak pwa aurait un double sens. L'un représenterait la clé qui assurerait les liens du nouveau migrant dans un autre pays, les souvenirs, les goûts, l'odeur de ces ingédiants assureraient les liens aux traditions, aux origines, aux histoires et à la capacité de 

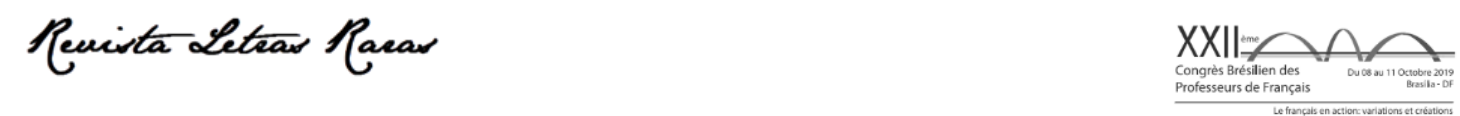

Actes du XXIlème Congrès brésilien des professeurs de français (dans Édition spéciale de la Revue Letras Raras 2020) ISSN : 2317-2347 - v. 9, Dossier Spécial (2020)

Todo o conteúdo da RLR está licenciado sob Creative Commons Atribuição 4.0 Internacional

résistance. Mais manger le diri ak pwa chez l'Autre pourrait signifier aussi une prise de conscience où le migrant accepterait le défi de chercher à vivre une nouvelle expérience telle celle vécue par tous ceux qui dépassent les frontières d'un pays:

Fiquei observando minha mãe preparar o arroz do meu pai...

Uma nova porção de arroz branco preparada por minha mãe. Desta vez, ela a levou, não na bandeja da cama, mas numa travessa prateada redonda do armário especial. Meu pai levantou-se na cama para recebê-la, e assim que minha mãe the estendeu a colher, porque ele sempre comia arroz com a colher, ele mergulhou-a imediatamente nele (DANTICAT, 2010, p. 222).

Danticat récupère, cherce à reconstruire l'origine familiale, marquée para la rencontre de I'Autre nord-américain. Elle réaffirme ses liens avec son pays natal et en privilégiant l'imaginaire de la distance, elle se réinvente dans le sens de faire revivre, de comprendre et d'accepter cette distance géographique mais aussi culturelle.

\section{Références :}

ANTOINE, R. La littérature franco-antillaise. Haiti, Guadeloupe et Martinique. Paris: Éditions Karthala, 1992.

BERNABÉ, J.; CHAMOISEAU, P.; CONFIANT, R. Éloge de la Créolité. Paris: Gallimard, 1989.

CÉSAIRE, A. Cahier d'un retour au pays natal. Paris: Présence Africaine, 1983.

DANTICAT, E. Brother, I'm Dying. New York: Alfred A. Knopf, 2007.

DANTICAT, E. Adeus Haiti. Trad. de Geraldo Galvão Ferraz. Rio de Janeiro: Agir, 2010.

DEPESTRE, R. Bonjour et adieu à la négritude. Paris: Laffont, 1980.

GLISSANT, É. Introdução a uma poética da diversidade. Trad. Enilce Albergária Rocha. Juiz de Fora: EdUFJF, 2005.

GLISSANT, É. Poétique de la Relation. Éditions du Seuil, 1990.

GLISSANT, É. Traité du Tout Monde. Paris: Gallimard, 1997.

HURBON, L. Le barbare imaginaire. Paris: Les éditions du Cerf, 1988.

MAXIMIN, D. Les fruits du cyclone. Une géopoétique de la Caraïbe. Paris: Editions du Seuil, 2006. 